Article

\title{
Minimizing the Health Risks from Hydrocarbon Contaminated Soils by Using Electric Field-Based Treatment for Soil Remediation
}

\author{
Irina Aura Istrate ${ }^{1}$, Diana Mariana Cocârţă ${ }^{2, *}$, Zucheng $\mathrm{Wu}^{3, *}$ and Mihaela Alexandra Stoian ${ }^{2}$ \\ 1 Department of Biotechnical Systems, Faculty of Biotechnical Systems Engineering, University Politehnica of \\ Bucharest, 313 Splaiul Independentei, 006042 Bucharest, Romania; irina_aura.istrate@upb.ro \\ 2 Department of Energy Production and Use, Faculty of Power Engineering, University Politehnica of \\ Bucharest, 313 Splaiul Independentei, 006042 Bucharest, Romania; stoian_mihaela20@yahoo.com \\ 3 Department of Environmental Engineering, Zhejiang University, Hangzhou 310058, China \\ * Correspondence: diana.cocarta@upb.ro (D.M.C.); wuzc@zju.edu.cn (Z.W.)
}

Received: 29 November 2017; Accepted: 15 January 2018; Published: 19 January 2018

\begin{abstract}
The present work addresses the assessment of human health risk from soil contaminated with total petroleum hydrocarbons (TPHs) due to crude oil pollution, with a particular focus on the polycyclic aromatic hydrocarbon $(\mathrm{PAH})$ group of carcinogenic and toxic substances. Given that the measured risk for human health exceeded the accepted level, the study considered an electrochemical remediation method. The laboratory-scale experiments were conducted by using an electric field-based treatment as a possible solution for the remediation of contaminated soil. After 20 days of treatment, while the voltage applied was $15 \mathrm{~V}$ (specific voltage of $1 \mathrm{~V} / \mathrm{cm}$ ), the hydrocarbon content was significantly reduced. The parameters measured to determine the overall remediation efficiency were $\mathrm{pH}$, redox potential, ionic strength, soil characteristics, voltage gradient, and zeta potential. The remediation degree observed during the experiments was around $50 \%$ for TPHs and $46 \%$ for PAHs. The applied remediation method resulted in significant removal efficiency of the tested contaminants from the soil. Consequently, the human health risk assessment for the new degree of contaminants in the soil was achieved. This data demonstrated to what extent the application of the remediation applied technology ensured an acceptable risk under the same exposure conditions for the industrial workers.
\end{abstract}

Keywords: risk assessment; PAHs; electrochemical remediation; contaminated soil

\section{Introduction}

In recent decades, the issue of soil pollution has increased due to rapid urbanization and industrialization. Unfortunately, contaminated soil is causing significant environmental problems due to the persistence of pollutants, which accumulate in soil and prove difficult to remove [1]. Moreover, contaminated soils are a key environmental concern for all industrialized countries, and, in particular, Europe and Romania. In Europe, according to data extrapolated to the whole of Europe and provided by the European Environment Agency [2], the estimate of the total number of potentially contaminated sites stands at around 2.5 million, of which about $14 \%$ (350,000 sites) are considered to be heavily contaminated and, hence, in need of immediate remediation measures. In Romania, the National Environmental Protection Agency drafted the National Inventory in 2014, which lists 1183 potentially contaminated sites and 210 contaminated sites, to give a total number of 1393 affected sites. The industries having significantly contributed to soil pollution in Romania are the mining and metallurgical industry, with 160 potentially contaminated sites; the petroleum industry, with 861 potentially contaminated sites; and the chemical industry, with 37 potentially contaminated 
sites [3]. On the other hand, as the proposal for a Soil Framework Directive was withdrawn by the European Commission in May 2014, Europe still lacks a common soil legislative instrument and European Union (EU) Member States have their own laws on soil protection. If soil contamination is the presence of a minor and unwanted contaminant in the natural environment (in our case study, the presence of polycyclic aromatic hydrocarbons in soil), soil pollution represents the introduction of contaminants into the natural environment that cause adverse change; so, specifically, the present work is about soil pollution with crude oil during oil exploration. Regarding soil contamination and risk assessment, some of the European Union member countries have already established procedures to assess and manage the risks posed by contaminated sites, while others are currently in the process of doing so. In this regard, the first significant European project was promoted by the German Environment Ministry and coordinated by the Federal Environment Agency (Umweltbundesamt, Dessau-Roßlau, Germania), and involved scientists from 16 European countries: Austria, Belgium, Denmark, Finland, France, Germany, Greece, Ireland, Italy, Netherlands, Norway, Portugal, Spain, Sweden, Switzerland, and the United Kingdom. The project was called "Concerted Action on Risk Assessment for Contaminated Sites in the European Union/CARACAS" (1996-1998) and was funded by the European Commission under the Environment and Climate Programme [4]. Other initiatives linked to CARACAS are NICOLE (Network for Industrially Contaminated Land in Europe), an industry-led concerted action programme; RACE (Risk Abatement Centre for Contaminated Sites in Central and Eastern European Countries); the EEA's European Topic Centre on Soil; the International Standards Organisation Technical Committee TC190 dealing with soil quality [4]; and TIMBRE (Tailored Improvement of Brownfield Regeneration in Europe), a European research project financed under the EU 7th Framework Programme, which Romania, through the National Agency for Environmental Protection and Technical University of Civil Engineering Bucharest, was part of.

As mentioned above, the sector that is mainly responsible for the organic contamination of soil in Romania is the petroleum industry, with all of its related activities (extraction, transportation, and processing of petroleum products). Crude petroleum is a complex mixture containing more than 17,000 identified chemical compounds [5]. Saturated and aromatic hydrocarbons represent the majority of non-polar fractions [5,6]. Polycyclic aromatic hydrocarbons (PAHs) are persistent in the environment due to their low water solubility and low volatility [7]. An overview of the main contaminants affecting soil in Europe indicated that, in 2012, PAHs accounted for $13.3 \%$ of the contaminants affecting soil [8]. Over the past decade, the treatment of these compounds has become a matter of interest for numerous authors [7]. In this context, various technologies such as bioremediation, chemical treatments, and physical treatments [7-10], have been applied to remediate soils, sediments, and groundwater. Despite efforts made over the last two decades, there is still no reliable technology for the remediation of contaminated soils [11,12]. Many technologies have been developed over the past years, but each handles a single type of contaminant or site condition [12]. Moreover, usually the sites are polluted simultaneously with different types of contaminants, which makes the remediation of these sites a complicated process.

This paper focuses on the application of a physical-chemical treatment that is based on an electric field applied to soils contaminated with PAHs due to crude oil pollution over time. The main variables that could influence overall treatment efficiency and were monitored during the scientific research were $\mathrm{pH}$, redox potential, ionic strength, soil characteristics, voltage gradient and zeta potential. The human health risk assessment related to the concentrations of contaminants before and after the application of the treatment, was also considered in this study. Therefore, the main objectives of this study were to (1) obtain information about the soil contamination level of Total Petroleum Hydrocarbons (TPHs) and PAHs; (2) apply the risk assessment procedure in accordance with the Romanian regulations and guidelines; (3) evaluate the remediation degree with regard to the electrochemical technique used for soil decontamination; (4) obtain information about the risk level once the remediation goals are achieved; and (5) evaluate the results obtained to provide useful information for the decision-making factors involved in the proper management of contaminated sites. 


\section{Working Methodology}

The working methodology has been divided into five phases. The first phase is the collection of samples of contaminated soil. The second phase consists of comparing the concentration of TPHs and PAHs found in the contaminated soil with those provided by the applicable Romanian regulations. The third phase involves measuring the incremental lifetime cancer risk (ILCR) resulting from PAH soil contamination by oil pollution. The next phase is the experimental research addressing the remediation of the contaminated soil, comparing new TPH and PAH concentrations in soil with allowed thresholds and determining the efficiency of the proposed treatment solution. In the final phase, the study conducted risk estimations for different remedial efficiency scenarios for the considered industrial area. In this manner, the study determined the influence of the electrochemical method, in respect to risk reduction, for different scenarios concerning the applied remediation technology: 1. no remediation; 2. electrochemical remediation for 10 days and 3. electrochemical remediation for 20 days.

\subsection{Site Description, Sampling and Analysis}

The soil samples were collected from an industrial area located in southeastern Romania. The contaminated soil was subjected to oil drillings, production, or storage activities. The samples of soil were taken according to the national standard procedure illustrated by State standard (STAS) 7184/1-84 [13] and following the Romanian regulation in force for the investigation of potentially contaminated sites: Order No. 184/1997 for the approval of the Environmental Balance Sheet Procedure [14]. A diagonal system for the soil sampling was considered and basic soil sampling tools, such as soil probes, were used. The number of sampling points was established according to the regulations in force, where it was specified that for an area of $1000 \mathrm{~m}^{2}$, a minimum number of four sampling points is required. In the present work, five soil samples were collected from an area of $1000 \mathrm{~m}^{2}$, from five different points. For the chemical analysis, the contaminated soil samples were physically combined and mixed in order to form a single homogeneous sample (according composite sampling protocol). The collected soil was stored at $4{ }^{\circ} \mathrm{C}$, transported to the laboratory, and further chemically analyzed.

By using the standard methods, SR ISO 13877:1999 [15] and SR EN ISO 16703:2011 [16], the Polycyclic Aromatic Hydrocarbons ( $\mathrm{PAH}$ ) and the Total Petroleum Hydrocarbons (TPHs), were determined. The soil sample was passed through a sieve with approximately $2 \mathrm{~mm}$ openings. For the sample extraction, 6 benches SOXHLET equipment (Heidolph, Schwabach, Germany) was used. An approximate $20 \mathrm{~g}$ portion of contaminated soil was extracted with $250 \mathrm{~mL}$ of high-performance liquid chromatography (HPLC) grade petroleum ether solvent. The extract was concentrated to a low solvent volume using a Heidolph rotary evaporator and eluted with hexane. After the extraction stage, the soil sample was transferred to a capped and sealed flask for gas-chromatographic analysis [17-19]. For the identification and quantification of PAHs existing in the extracted sample, a HPLC system, model Agilent 1200 series (Agilent Technologies, Waldbronn, Germany) equipped with photodiode array detector, was used. The considered PAHs in the present work are naphthalene, acenaphthene, fluorene, phenanthrene, anthracene, fluoranthene, pyrene, benzo-a-anthracene, chrysene, benzo-b-fluoranthene, benzo-k-fluoranthene, benzo-a-pyrene, dibenzo-a, h-anthracene, benzo-ghi-perylene and indeno(1,2,3-cd)pyrene. These are found in the U.S. EPA list of 16 PAHs, issued by the U.S. Environmental Protection Agency (EPA, Washington, DC, USA) in 1976, known for their negative influence on humans [20,21].

\subsection{Human Health Risk Assessment Methodology}

Quantification of the Incremental Lifetime Cancer Risk (ILCR) was performed to estimate the exposure risk of soil contamination with carcinogenic chemicals. In this manner, it was possible to evaluate the risk of the investigated contaminated site and show how to use the risk-based approach to achieve the remediation goals on sites. 
The methodology used for the assessment of risks on human health was the classical method with multiple pathways. This methodology is already widely used for the environmental assessment of industrial facilities and has been used in Europe. The methodology includes four key phases: 1. Hazard identification (review key research to identify any potential health problems that a chemical can cause); 2. Exposure assessment (determine the amount, duration, and pattern of exposure to the chemical); 3. Dose-response assessment (estimation of the relationship between dose, or level of exposure to a substance, and the incidence and severity of an effect); and 4. Risk characterization (assess the risk for the chemical to cause cancer or other illnesses in the general population) [22]. All of these four steps could be influenced by different factors, such as the degree of pollutant concentration in the soil, the pollutant type, and the exposure scenario. The assessment of total exposure within the framework of the risk assessment requires complex knowledge from various disciplines.

Throughout the present study, the human health risk was assessed by considering the industrial use of the soil, based on the different electrochemical solution scenarios proposed for soil remediation. Specifically, it was presumed that the electrochemically treated soil in different experimental conditions was placed to their initial location for industrial use. In these conditions, the human exposure was quantified according to U.S. EPA equations [23], taking into account exposure through accidentally ingested soil and dermal contact, as follows:

$$
\text { Dose } \left._{\text {s.i. }}=\left(C_{\text {cont }} \times I R \times F I\right) \times\left(B W^{-1}\right) \times\left((E D \times E F) \times A T^{-1}\right)\right) \times C F
$$

Therefore, exposure through accidental ingestion of contaminated soil (Dose s.i. $_{-}-\mathrm{mg} / \mathrm{kg} /$ day) was calculated considering the concentration of the contaminant in the soil $\left(C_{\text {cont }}-\mathrm{mg} / \mathrm{kg}_{\mathrm{dw}}\right)$, the ingestion rate (IR—mg soil/day), and the fraction ingested from the contaminated source (FI—unitless) [23].

$$
\text { Dose } \left._{\text {d.c. }}=\left(\left(C_{\text {cont }} \times S A \times A F \times A B S\right) \times B W^{-1}\right) \times\left((E F \times E D) \times A T^{-1}\right)\right) \times C F
$$

For the exposure through dermal contact $\left(\right.$ Dose $_{\text {d.c. }}-\mathrm{mg} / \mathrm{kg} /$ day), the parameters considered for dose calculation are the concentration of the contaminant in the soil $\left(C_{\text {cont }}-\mathrm{mg} / \mathrm{kg} \mathrm{dw}\right)$, the surface area of skin available for contact $\left(S A-\mathrm{cm}^{2} /\right.$ day), the soil-to-skin adherence factor $\left(A F-\mathrm{mg} / \mathrm{cm}^{2}\right)$, and the fraction absorbed across the skin (ABS-unitless) [23].

From both equations, BW represents body weight, $C F$ represents the conversion factor $\left(10^{-6} \mathrm{~kg} / \mathrm{mg}\right), E F$ represents exposure frequency (days/year), $E D$ represents exposure duration (years), and $A T$ represents average time (days). Incremental lifetime cancer risk (ILCR) can be expressed as:

$$
\mathrm{ILCR}=D \times S F
$$

where ILCR represents Individual Cancer Risk (unitless), $D$ represents the daily dose $(\mathrm{mg} / \mathrm{kg} /$ day), and $S F$ represents the slope factor $\left((\mathrm{mg} / \mathrm{kg} / \text { day })^{-1}\right)$.

\subsection{Electrochemical Treatment}

As part of the electrochemical (electrokinetic) treatment, a low-density direct current was applied by two electrodes inserted into the polluted soil. A current promotes the movement of pollutants in the pore fluid towards the electrode chambers, where they are finally collected and treated. Therefore, this technique is recommended for application with fine and low-permeability soils [24-27] and has been mainly applied to the treatment of soils polluted by metals, due to the property to move the ionic species [28]. This treatment has emerged as an alternative to conventional soil treatments due to its peculiar advantages, namely the capability of treating fine and low-permeability materials, as well as achieving a high yield in the removal of salt content and inorganic and organic pollutants [29]. The application of this electric field-based treatment involves the use of a constant voltage applied to two electrodes (one is the anode and the other is the cathode). Several physical and chemical processes take place during the treatment implementation. The physical processes, which result in the mobilization and transportation of contaminants towards the anode or the cathode electrodes 
for subsequent removal out of the contaminated soil [30], are electromigration and electroosmosis. Electromigration is the movement of ionic species in an electric field towards the electrode of opposite charge $[27,30]$. The electroosmotic flux represents the movement of water mass towards the cathode, under the influence of the electric field $[27,30,31]$. Regarding the chemical processes that take place, we can mention the electrolysis of water, adsorption/desorption of contaminants on the soil particle surfaces, redox reactions, and acid/basic reactions [27,30].

In order to develop the electrokinetic research, an experimental setup was used, consisting of an electrochemical cell, with dimensions $150 \mathrm{~mm} \times 150 \mathrm{~mm} \times 150 \mathrm{~mm}(\mathrm{~L} \times 1 \times \mathrm{h})$, with electrodes inside connected to a power supply. The overall diagram of the experimental system is shown in Figure 1.

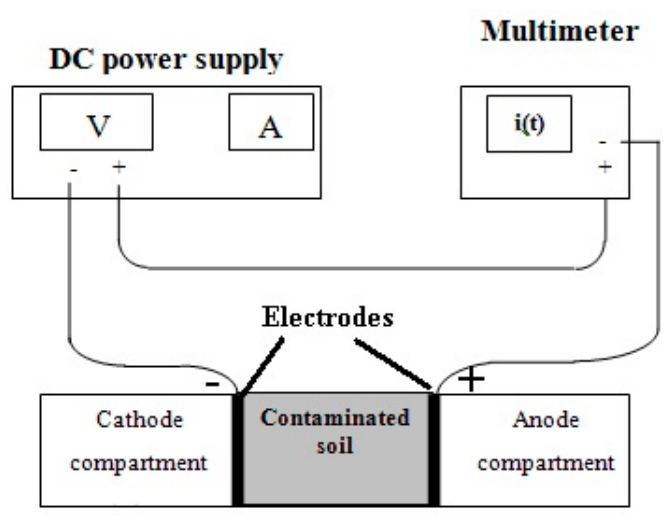

Figure 1. Diagram of the experimental setup.

The contaminated sample was inserted into the electrochemical cell and was further compacted so that no empty space could exist. In order to ensure the occurrence of all physical and chemical processes, the humidity of the soil was maintained at a minimum of $20-30 \%$ by adding water when necessary. The experiment lasted for 20 days. Bulk soil samples were collected from the anode and cathode areas, over the entire depth of the cell. The samples were then mixed in order to obtain a homogenous probe. An intermediate soil was created in the same manner, by sampling 10 days after the experiment was started. The results from this experiment, and the final results, are illustrated in the following paragraphs.

\section{Results and Discussion}

\subsection{Electrochemical Removal of Hydrocarbons from the Contaminated Soil}

The main characteristics of the investigated soil were that the $\mathrm{pH}$ was around 5.87 (there is a tendency for the acidification of the soil sample) and the humidity was around $14.82 \%$. The concentration level of TPHs and PAHs identified in the soil are presented in Table 1.

Table 1. Initial characterization of soil sample $\left[\mathrm{mg} / \mathrm{kg}_{\mathrm{dw}}\right]$.

\begin{tabular}{cccc}
\hline \multirow{2}{*}{ Analyzed Parameter } & \multicolumn{2}{c}{ Industrial Areas } & \multirow{2}{*}{ Determined Values } \\
\cline { 2 - 3 } & Alert Threshold & Intervention Threshold & \\
\hline Total Petroleum Hydrocarbons (TPHs) & 1000 & 2000 & 14,725 \\
Polycyclic Aromatic Hydrocarbons (EPAHs) & 25 & 150 & 103.16 \\
\hline
\end{tabular}

As illustrated in Table 1, the results from the analytical procedures, compared with the regulation in force, revealed that pollution levels exceeded the alert thresholds for the industrial use of soil and were below the intervention thresholds. As the hazard level was not given by the concentration level of contaminants (TPHs concentration in soil $=14,725 \mathrm{mg} / \mathrm{kg}_{\mathrm{dw}}$ with respect to $\Sigma \mathrm{PAHs}=103.16 \mathrm{mg} / \mathrm{kg} \mathrm{dw}_{\mathrm{w}}$ ), 
but by the degree of toxicity of the analyzed compounds, Benzo[a]pyrene $(\mathrm{BaP})$ was the most toxic of the parent PAHs with a Slope Factor of $1.2 \times 10(\mathrm{mg} / \mathrm{kg} / \text { day })^{-1}$, and deeper investigation was necessary. A remediation solution for the contamination problem was proposed and risk assessment before and after the remediation process, was considered. The electrochemical treatment was tested in laboratory-scale experiments.

The experimental research was conducted for 20 days with a soil quantity of $6 \mathrm{~kg}$. A voltage of approximately $15 \mathrm{~V}$ was applied. During the experiments, a series of parameters were monitored: $\mathrm{pH}$, redox potential (ORP), current intensity, energy consumption, and treatment efficiency.

The values for the $\mathrm{pH}$ ranged between 3.93 and 10.32, but the main aim was to obtain values close to 7 in order to create a more suitable environment in the soil after the application of the electrochemical remediation. For this purpose, the ORP was monitored and when the values went near or below 0 , the polarity of the experiment was changed. ORP was assessed to have better control of the oxidation reactions that took place during the experiment (see Figure 2). The influence of ORP on $\mathrm{pH}$ was a secondary consequence.

To ensure proper development of the electrochemical processes (improving the electrical conductivity and consequently stimulating the oxidation and reduction reactions), $20-25 \%$ of soil moisture content was obtained by adding a suitable amount of deionized water. The higher the soil moisture content, the better the electrochemical processes are expected to function. Additionally, the oxidation reactions occurred near the anode area and, as a result, the ORP values suggested that the oxidation reactions occurred more rapidly than the reduction reactions taking place near the cathode area. A uniform decontamination of the soil requires a change in the polarity of the electrodes to increase the treatment efficiency. A consequence of this approach is also the non-uniformity of the $\mathrm{pH}$ in the entire soil sample (usually, in the anode area there is an acid front and in the cathode area there is a basic front). The same behavior is also identified with regard to the ORP parameter.

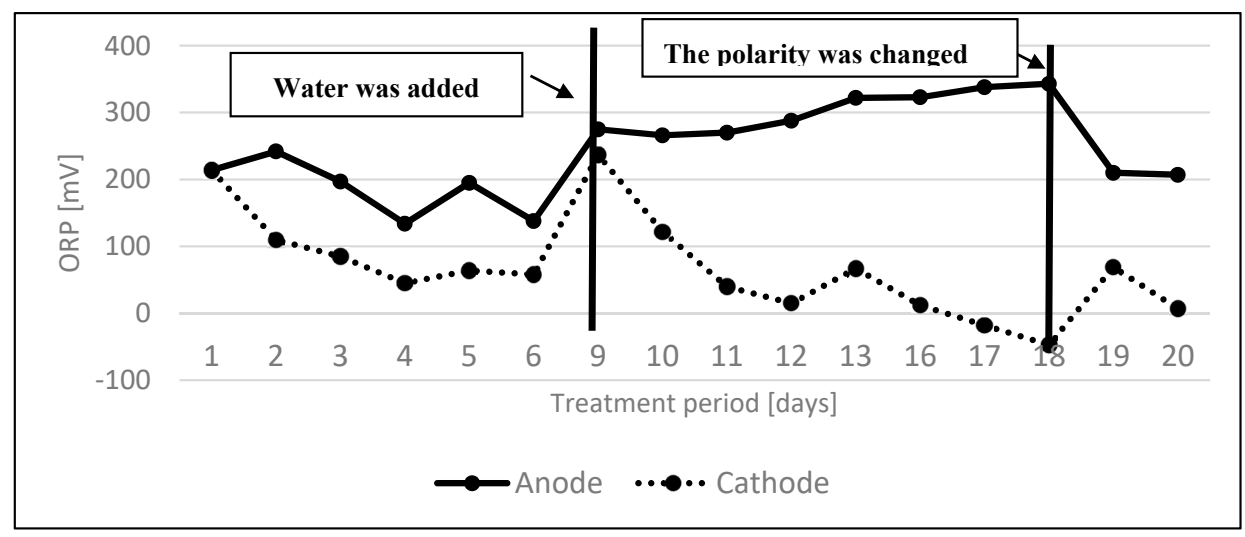

Figure 2. Redox potential (ORP) trend in the experimental research.

During the experiment, the current intensity was measured. The maximum value was $0.19 \mathrm{~A}$, recorded at the beginning of the experiment, while the minimum value was $0.03 \mathrm{~A}$. Energy consumption plays an important role in the development of sustainable technologies for the remediation of contaminated soils, with real consequences on cost-effectiveness. Therefore, another parameter that was measured was energy consumption, using an electronic power meter-type KGS02-01/1109. After 10 days, $6.5 \mathrm{kWh}$ were consumed, while at the end of the experimental study, this parameter reached a value of approximately $14.7 \mathrm{kWh}$. Obviously, as shown below, an increase in the envisaged remediation time (at the same voltage) allowed for better removal of the contaminant, but this improvement was counterbalanced by the fact that a higher time of remediation (e.g., 20 days or longer) results in higher energy expenditure and a higher remediation strategy cost.

The treatment efficiency was the parameter that had real importance in determining the success of the conducted experiment. Figure 3 shows that the degradation efficiency of the electrochemical 
solution for $\Sigma$ PAHs removal had the same order of magnitude as for the TPHs. On the other hand, the degradation efficiency was higher for both $\Sigma$ PAHs and TPHs when the time of soil electrical treatment was increased from 10 to 20 days. It was demonstrated that the removal of PAHs could reach from $16 \%$ (after 10 days of the remediation process) to $46 \%$ (after 20 days of the remediation process), while removal of the heavy TPHs could reach from $17 \%$ (after 10 days of the remediation process) to $50 \%$ (after 20 days of the remediation process). Concerning the trend of the remediation degree of the tested method, it was observed that even by increasing the period, the results were better at the end of the treatment period (the initial concentration of PAHs in the soil was $103.6 \mathrm{mg} / \mathrm{kg}_{\mathrm{dw}}$, decreasing to $87.06 \mathrm{mg} / \mathrm{kg}_{\mathrm{dw}}$ after 10 days (ElectroChemical treatment after 10 days-EC10) and to $55.49 \mathrm{mg} / \mathrm{kg} \mathrm{dw}$ after 20 days (EleCtrochemical treatment after 20 days-EC20); and the initial concentration of TPHs in the soil was $14,725 \mathrm{mg} / \mathrm{kg}_{\mathrm{dw}}$, decreasing to $12,242 \mathrm{mg} / \mathrm{kg}_{\mathrm{dw}}$ in EC10 and to $7324.50 \mathrm{mg} / \mathrm{kg}_{\mathrm{dw}}$ in EC20) and the remediation degree from one stage of the process to another dropped significantly. An overview of the tendency of the remediation degree to correlate with soil remediation time, is shown in Figure 4. The trend for both TPHs and $\Sigma$ PAHs was observed where the remediation degree was higher in the second part of the experiment and increased as the time of remediation increased. These results are maintained by different authors in the literature [29-31], which indicates that electrochemical treatment efficiency increases along with an increasing treatment period.

Nationally, accordingly to the National Strategy and the National Action Plan for the Management of Contaminated Sites in Romania [32], the highest number of contaminated sites is found in the oil extraction industry (738 sites), with an additional 178 sites in the extractive industry and 61 sites in the petroleum industry. These numbers show that the decontamination of polluted sites is, and will remain in the coming years, a major issue for Romania. Even in the absence of accurate information on the contamination degree of the contaminated sites mentioned above, the results obtained during the present research could be considered useful for the future management of this environmental issue.

As mentioned above, our choice was to assess the degradation efficiency of TPHs and PAHs in a pilot-scale electrochemical cell, with lab-scale experiments, in order to analyze and evaluate the effects and optimal design of an electrochemical solution for the remediation of contaminated sites. For this purpose, we collected typical soil samples and remediated them in the laboratory to obtain clear information with better control of the process. Consequently, the interferences that may occur during field testing were minimized, and we obtained significant results prior to applying the electrochemical solution to the in-field remediation application. Of course, a soil map indicating the PAHs in excess would be better to clearly describe the situation of the contaminated sites in the framework of real-scale applications. Additionally, it must be specified that, during previous research $[10,25,27]$, soil samples were usually collected from areas near the two electrodes.

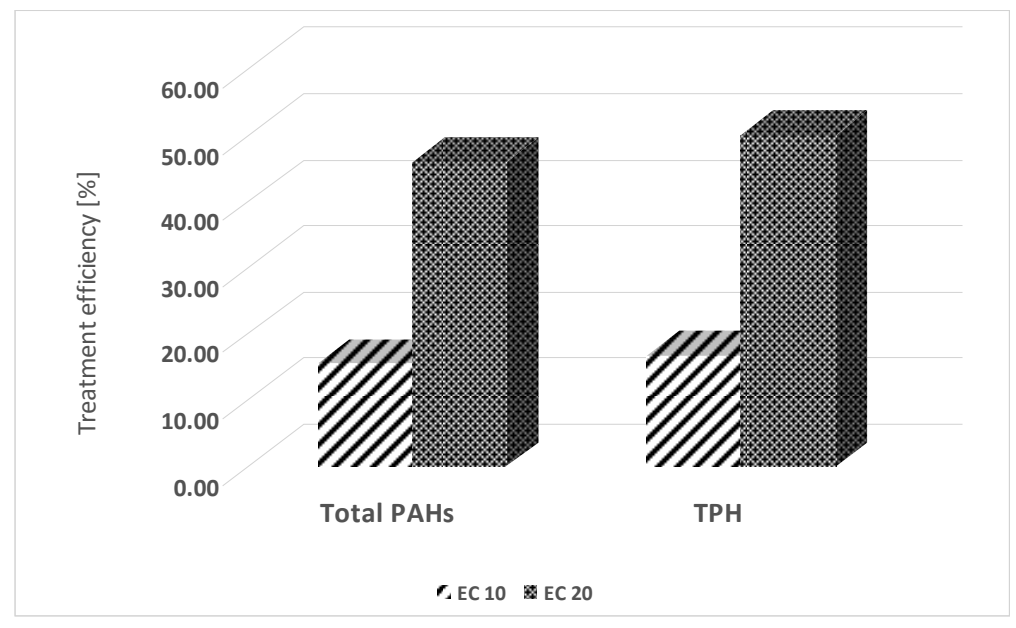

Figure 3. Degradation efficiency of PAHs and TPHs in soil across the electrochemical remediation. 


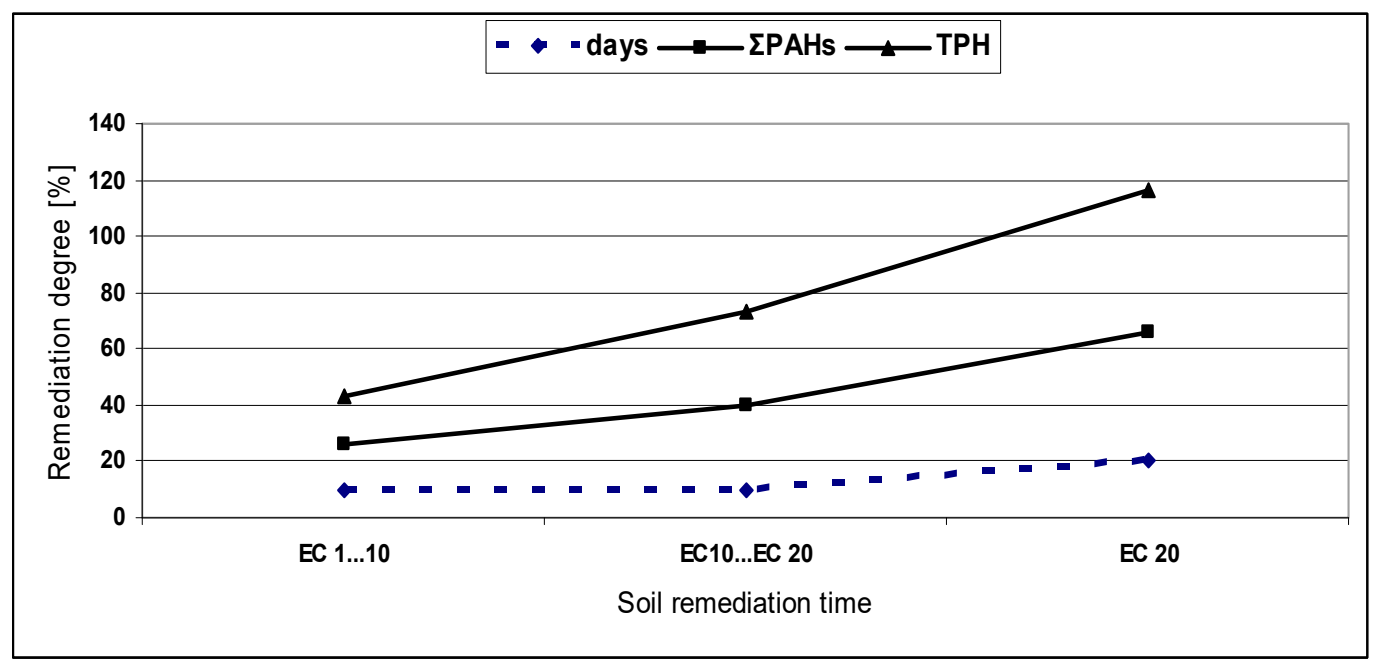

Figure 4. Remediation degree of PAHs and TPHs in soil as a function of time.

\subsection{Risk Assessment of PAH-Contaminated Soil}

Further, health risk assessment was performed for each considered scenario for the industrial use of soil. The exposure to PAHs in soil was assessed since it has been demonstrated that exposure to some of these contaminants can cause an increase in the incidence of cancer. The circumstances of exposure that were taken into account, in the industrial use of soil, were the accidental ingestion of contaminated soil and dermal penetration, correlated with the exposure conditions in the framework of the industrial use of soil. The exposure parameters were selected considering the equations provided by the U.S. EPA [33], as illustrated in Table 2. The Incremental Lifetime Cancer Risk was calculated for industrial workers for each exposure scenario. For the assessment of ILCR, the Slope Factor was equal to $1.2 \times 10(\mathrm{mg} / \mathrm{kg} / \text { day })^{-1}$, defining the Benzo[a]pyrene $(\mathrm{BaP})$ compound, the most toxic PAH according to the Californian Environmental Protection Agency, Office of Environmental Health Hazard Assessment (OEHHA) [33]. Considering this, we selected the most conservative approach for the assessed scenarios.

Table 2. Exposure parameters [34,35].

\begin{tabular}{|c|c|c|}
\hline Parameter Category & Units & Industrial Workers \\
\hline \multicolumn{3}{|l|}{ Common parameters } \\
\hline Body weight (BW) & $\mathrm{kg}$ & 80 \\
\hline Average time (AT) & days & 9125 \\
\hline Lifetime (LT) & years & 70 \\
\hline Exposure frequency $(\mathrm{EF})$ & days/year & 250 \\
\hline \multicolumn{3}{|c|}{ Exposure through accidental soil ingestion-specific parameters } \\
\hline Soil ingestion rate (IR) & $\mathrm{mg} /$ day & 50 \\
\hline Fraction ingested from contaminated source (adults) & unitless & 0.3 \\
\hline \multicolumn{3}{|l|}{ Exposure through dermal contact-specific parameters } \\
\hline Skin surface area available to contact (SA) & $\mathrm{cm}^{2} / \mathrm{d}$ & 3527 \\
\hline Soil-to-skin adherence factor (AF) & $\mathrm{mg} / \mathrm{cm}^{2}$ & 0.2 \\
\hline Absorption factor (ABS) & unitless & 0.13 \\
\hline
\end{tabular}

The accepted level of cancer risk has been a subject widely discussed in the literature [36,37]. If, initially and generally, an additional lifetime cancer risk of one in a million $\left(10^{-6}\right)$ was considered most frequently as the acceptable value for individual cancer risk, the management of risks posed by soil contamination later changed this consideration. In the United States, the National Oil and 
Hazardous Substances Pollution Contingency Plan (NCP) [38] provides information on cancer risk indices related to Superfund site remediation and indicates an acceptable cancer risk range of $10^{-4}$ to $10^{-6}$. This typical range is indicated also by other authorities and authors in different countries $[39,40]$.

The majority of PAHs have been classified by the U.S. EPA as probable human carcinogens, being commonly believed and demonstrated through different research studies, to have a real contribution to the development of human cancers [41]. Evidence indicates that mixtures of PAHs are carcinogenic to humans. Initially, evidence arose from occupational studies on workers exposed to mixtures containing PAHs, and further long-term studies have demonstrated an increased risk of, predominantly, skin and lung, but also bladder and gastrointestinal, cancers [42].

In the present study, the carcinogenic risk for industrial workers' receptors showed that the worst scenario is where no remediation method is applied. In this scenario, the Incremental Lifetime Cancer Risk is $1.13 \times 10^{-3}$ (as illustrated in Table 3). Consequently, the assessed ILCR exceeds the acceptable cancer risk range of $10^{-4}$ to $10^{-6}$.

Table 3. Health risk assessment based on different experimental scenarios of the electrochemical experiments.

\begin{tabular}{cccc}
\hline Experimental Conditions & $\begin{array}{c}\text { Contaminated Soil } \\
\text { without } \\
\text { Remediation }\end{array}$ & $\begin{array}{c}\text { Electrochemical } \\
\text { Treatment } \\
\text { (10 Days) }\end{array}$ & $\begin{array}{c}\text { Electrochemical } \\
\text { Treatment } \\
\text { (20 Days) }\end{array}$ \\
\hline Scenarios & Scenario 1 & Scenario 2 & Scenario 3 \\
Incremental Lifetime Cancer Risk & $1.13 \times 10^{-3}$ & $9.54 \times 10^{-4}$ & $6.08 \times 10^{-4}$ \\
\hline
\end{tabular}

The remediation method of the electrochemical treatment for 10 days showed a decrease in risk from $1.13 \times 10^{-3}$ to $9.54 \times 10^{-4}$. This is in line with the acceptable range of increased cancer incidence risk, but afterwards the electrochemical treatment duration was extended to 20 days in order to assess to what extent the experimental conditions have an influence on ILCR. The increase in the treatment period to 20 days led to a reduction in ILCR of $46 \%$ (Table 3).

The results showed that, in the considered exposure scenario, ILCR is strictly related to the concentration of PAHs in the soil. The application of the proposed remediation method in the present research led to a $15.61 \%$ reduction in PAHs in the soil after 10 days and a $46.21 \%$ reduction after 20 days. The same trend was observed with regard to ILCR. Therefore, in the case of no treatment, EC10: EC20 corresponded to PAH concentrations of $103.16 \mathrm{mg} / \mathrm{kg}_{\mathrm{dw}}: 87.06 \mathrm{mg} / \mathrm{kg}_{\mathrm{dw}}: 55.49 \mathrm{mg} / \mathrm{kg}_{\mathrm{dw}}$, and ILCR values of $1.13 \times 10^{-3}: 9.54 \times 10^{-4}: 6.08 \times 10^{-4}$.

\subsection{Influence of Electrochemical Treatment of Soil on Hydrocarbon Degradation Efficiency and Risk to Humans}

The risk assessment performed for the investigated site, if no remedying method was applied and for different scenarios of the proposed remediation method, calculated various levels of risk for the same exposure conditions and the use of soil (industrial use of soil). The remedying methods, with the soil concentration observed and related risk levels, are presented in Table 4.

Table 4. Level of risk according to the concentration of PAHs in the soil.

\begin{tabular}{ccc}
\hline Test & Concentration in Soil $\left[\mathbf{m g} / \mathbf{k g}_{\text {d.w. }}\right]$ & Risk Level \\
\hline Without remediation & 103.16 & $1.13 \times 10^{-3}$ \\
EC10 & 87.06 & $9.54 \times 10^{-4}$ \\
EC20 & 55.49 & $6.08 \times 10^{-4}$ \\
\hline
\end{tabular}

Figures 5 and 6 indicate that the degradation of TPHs and PAHs shows similar behavior throughout the experimental research, while the ILCR from PAH-contaminated soil decreases when the TPH concentration in the soil is reduced. As a general trend from the experiments performed, 
a higher period of electroremediation gave a lower ILCR value. It is true that a longer electrochemical remediation time results in a lower concentration of contaminants in soil with a positive influence on the ILCR, but, in this case, deeper reflection on the cost-benefit analysis is required.



Figure 5. Degradation efficiency of PAHs and TPHs in soil during the electrochemical remediation.

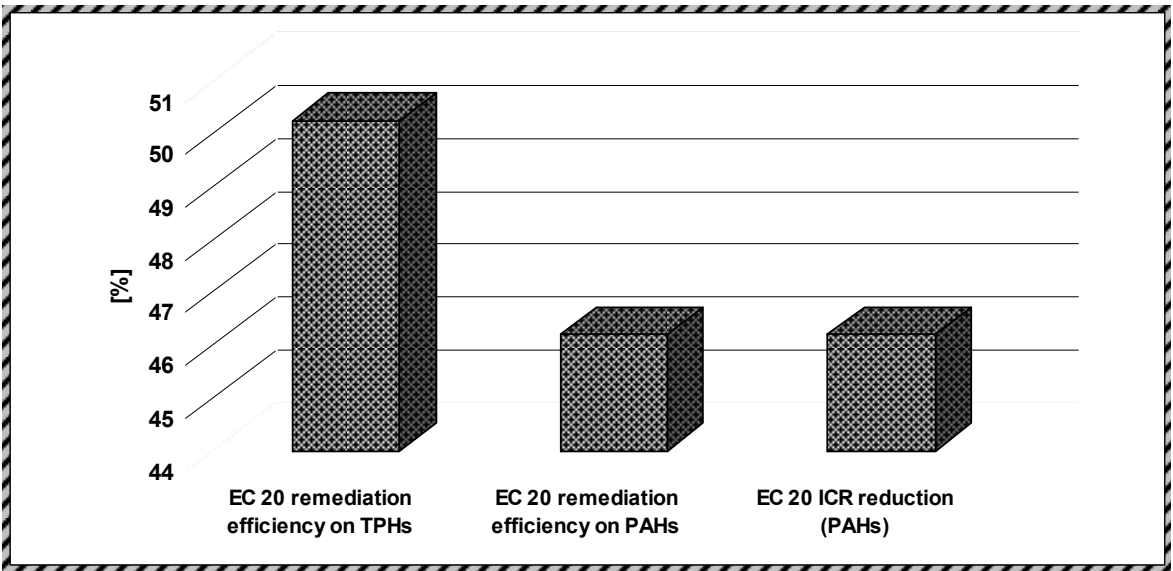

Figure 6. Degradation efficiency of PAHs and TPHs in soil during the electrochemical remediation.

The evaluation of the efficiency of hydrocarbon degradation in soil based on different experimental scenarios of the electrochemical method, showed, over time, the important relationship between the removal of total petroleum hydrocarbons and the reduction of the considered polycyclic aromatic hydrocarbons from the soil (Table 5).

Table 5. Efficiency of hydrocarbon degradation in soil based on different experimental scenarios of the electrochemical experiments.

\begin{tabular}{|c|c|c|}
\hline Experimental Conditions & \multirow{2}{*}{$\begin{array}{l}\text { Electrochemical } \\
\text { Treatment } \\
\text { (10 Days) }\end{array}$} & \multirow{2}{*}{$\begin{array}{c}\text { Contaminated Soil without Remediation } \\
\text { after Electrochemical Treatment } \\
\text { (20 Days) }\end{array}$} \\
\hline $\begin{array}{c}\text { Efficiency on Hydrocarbon } \\
\text { Degradation in Soil }\end{array}$ & & \\
\hline$\Sigma \mathrm{PAHs}$ & $15.61[\%]$ & $46.21[\%]$ \\
\hline TPHs & $16.87[\%]$ & $50.26[\%]$ \\
\hline
\end{tabular}

\section{Conclusions}

The assessment of risk to humans from our studied contaminated site indicated that a contamination of $14,275 \mathrm{mg} / \mathrm{kg}_{\mathrm{dw}}$, corresponding to a concentration of PAHs equal to $103.16 \mathrm{mg} / \mathrm{kg}_{\mathrm{dw}}$, 
caused a risk level of $1.13 \times 10^{-3}$. A removal rate of $16.87 \%$ for TPHs and $15.61 \%$ for PAHs was obtained when the electrochemical remedial method was applied for a test period of 10 days, and when doubling the treatment period, rates of $46.21 \%$ for TPHs and $50.26 \%$ for PAHs, were obtained. The reduction of TPHs in soil, and as a consequence the decrease of PAH concentration levels, resulted in an acceptable value of incremental lifetime cancer risk (ILCR). The results obtained showed that ILCR depends on the considered scenario and is directly related to the remediation rate of PAHs in the soil: a PAH reduction of $16.61 \%$ (Scenario 2) led to a $15.58 \%$ decrease in ILCR, while a PAH reduction of $50.26 \%$ (Scenario 2 ) led to a $46.20 \%$ decrease in ILCR.

The results of the risk assessment obtained for the considered scenarios can be useful in making decisions with respect to the management of contaminated sites, but also in improving the assessment of soil quality by including hazardous contaminants, such as carcinogenic PAHs. In this manner, it is possible to identify risk-based strategies to promote high-efficiency remediation methods with a low impact on the environment.

Acknowledgments: This work was supported by a grant from the Romanian National Authority for Scientific Research and Innovation, CNCS-UEFISCDI, project number PNII-RU-TE-2014-4-2348/ REMPET, by University POLITEHNICA of Bucharest through the "Excellence Research Grants" Program, UPB-GEX. Identifier: UPB-EXCELENT $\breve{A}-2016$, Contract No. 42/26.09.2016 (OZOSOL) and PROVED ID P_40_301, SMIS-CSNR:105707, ctr. 78/08.09.2016.

Author Contributions: Irina Aura Istrate prepared the experiments and analyzed the data for the implementation of the electrochemical treatment; Diana Mariana Cocârţă analyzed the data from the experimental research and drafted the human health risk assessment from the contaminated soil for all proposed scenarios; Zucheng Wu helped with the analysis of the data during and at the end of the electrochemical experiments and participated in drafting the final conclusions; and Mihaela Alexandra Stoian assisted with the bibliographical study of the human health risk method and contributed to the assessment of human health risk posed by the contaminated soil, and the drafting of the paper.

Conflicts of Interest: The authors declare no conflict of interest.

\section{References}

1. Bocos, E.; Fernandez-Costas, C.; Pazos, M.; Sanroman, A.M. Removal of PAHs and pesticides from polluted soils by enhanced electrokinetic-Fenton treatment. Chemosphere 2015, 125, 168-174. [CrossRef] [PubMed]

2. European Environment Agency. Progress in Management of Contaminated Sites. Indicator Assessment I Data and Maps. 2014. Available online: https:/ / www.eea.europa.eu/downloads/a29faf166f9e45f78e3ae107e72d957c/ 1441389583/assessment.pdf (accessed on 25 November 2017).

3. Boroş, M.N.; Micle, V.; Rogozan, G.C.; Sur, I.M. Method of treating contaminated brownfields using green technologies. In Proceedings of the International Conference Contaminated Sites, Bratislava, Slovakia, 12-13 September 2016.

4. Panagos, P.; Van Liedekerke, M.; Yigini, Y.; Montanarella, L. Contaminated sites in Europe: Review of the current situation based on data collected through a European network. J. Environ. Public Health 2013, 2013, 158764. Available online: http:/ / dx.doi.org/10.1155/2013/158764 (accessed on 25 November 2017). [CrossRef] [PubMed]

5. Daghio, M.; Aulenta, F.; Vaiopoulou, E.; Franzetti, A.; Arends, J.; Sherry, A.; Suarez, A.; Head, I.; Bestetti, G.; Rabaey, K. Electrobioremediation of oil spills. Water Res. 2017, 114, 351-370. [CrossRef] [PubMed]

6. Head, I.M.; Jones, D.M.; Roling, W.F.M. Marine microorganisms make a meal of oil. Nat. Rev. Microbiol. 2006, 4, 173-182. [CrossRef] [PubMed]

7. Ferrarese, E.; Andreottola, G.; Oprea, I.A. Remediation of PAH-contaminated sediments by chemical oxidation. J. Hazard. Mater. 2008, 152, 128-139. [CrossRef] [PubMed]

8. European Environment Agency (EEA). Overview of Contaminants Affecting Soil and Groundwater in Europe. 2011. Available online: http://www.eea.europa.eu/data-and-maps/figures/overview-ofcontaminants-affecting-soil-and-groundwater-in-europe (accessed on 25 November 2017).

9. Pazos, M.; Rosales, E.; Alcántara, T.; Gómez, J.; Sanromán, M.A. Decontamination of soils containing PAHs by electroremediation: A review. J. Hazard. Mater. 2010, 177, 1-11. [CrossRef] [PubMed] 
10. Istrate, I.A.; Cocârță, D.M.; Neamțu, S.; Cirlioru, T. The assessment of an alternative treatment for PCB polluted soils in the romanian context-Bench scale tests. Water Air Soil Pollut. 2013, 224, 1516. [CrossRef]

11. Cioca, M.; Cioca, L.I.; Duta, L. Web Technologies and Multi-criteria Analysis Used in Enterprise Integration. Stud. Inform. Control 2011, 20, 129-134. [CrossRef]

12. Camaselle, C.; Chirakkara, R.A.; Reddy, K.R. Electrokinetic-enhanced phytoremediation of soils: Status and opportunities. Chemosphere 2013, 93, 626-636. [CrossRef] [PubMed]

13. STAS 7184/1-84 Soils. Sampling for Pedologycal and Agrochemical Investigations. Available online: http:/ / magazin.asro.ro/en/standards/hierarchical-ics/2/13.080.01 (accessed on 25 November 2017).

14. Romanian Order No. $184 / 1997$ of the Minister of Waters, Forests and Environmental Protection (MWFEP) on the Approval of the Regulation Establishing the Procedure for Environmental Audit. 1997. Available online: http:/ / www.mmediu.ro/app/webroot/uploads/files/OM-184-1997-bilant-de-mediusi-OM-756-1997-evaluarea-poluarii-mediului.pdf (accessed on 25 November 2017).

15. ISO 13859:2014 Soil Quality-Determination of Polycyclic Aromatic Hydrocarbons (PAH) by Gas Chromatography (GC) and High Performance Liquid Chromatography (HPLC). 2014. Available online: https:/ / www.iso.org/standard/54337.html (accessed on 25 November 2017).

16. ISO 16703:2004 Soil Quality_Determination of Content of Hydrocarbon in the Range C10 to C40 by Gas Chromatography. 2004. Available online: https://www.iso.org/standard/39937.html (accessed on 25 November 2017).

17. Agilent Technologies. Polycyclic Aromatic Hydrocarbon Analysis Using an Agilent JEW DB-5ms Ultra Inert Capillary GC Column; Agilent Application 5989-9181EN; Agilent Technologies: Santa Clara, CA, USA, 2008.

18. Agilent Technologies. Synchronous SIM/Scan Low-Level PAH Analysis Using the Agilent Technologies 6890/5975 Inert GC/MSD; Agilent Application 5989-4184EN; Agilent Technologies: Santa Clara, CA, USA, 2009.

19. Cocârţă, D.M.; Stoian, M.A.; Karademir, A. Crude Oil Contaminated Sites: Evaluation by Using Risk Assessment Approach. Sustainability 2017, 9, 1365. [CrossRef]

20. Zelinkova, Z.; Wenzl, T. The Occurrence of 16 EPA PAHs in Food-A Review. Polycycl Aromat Compd. 2015, 35, 248-284. [CrossRef] [PubMed]

21. Samburova, V.; Zielinska, B.; Khlystov, A. Do 16 Polycyclic Aromatic Hydrocarbons Represent PAH Air Toxicity? Toxics 2017, 5. [CrossRef] [PubMed]

22. Environmental Risk Assessment (EEA). Approaches, Experiences and Information Sources; Environmental Issue Report No. 4; WHO Environmental Risk Assessment: Geneva, Switzerland, 1998; Chapter 5, ISBN 92-9167-080-4.

23. U.S. EPA. Risk Assessment Guidance for Superfund: Human Health Evaluation Manual, Part A; Office of Emergency and Remedial Response; U.S. Environmental Protection Agency: Washington, DC, USA, 1989; Volume 1.

24. Yeung, A.T.; Gu, Y.Y. A review on techniques to enhance electrochemical remediation of contaminated soil. J. Hazard. Mater. 2011, 195, 11-29. [CrossRef] [PubMed]

25. Rada, E.C.; Istrate, I.A.; Ragazzi, M.; Andreottola, G.; Torretta, V. Analysis of Electro-Oxidation Suitability for Landfill Leachate Treatment through an Experimental Study. Sustainability 2013, 5, 3960-3975. [CrossRef]

26. Li, X.; Li, X.; Tang, S.; Yang, J.; Li, W.; Luo, B.; Yu, Y.; Li, S. High selectivity of benzene electrochemical oxidation to p-benzoquinone on modified $\mathrm{PbO}_{2}$ electrode. Appl. Surf. Sci. 2014, 311, 357-361. [CrossRef]

27. Oprea, I.A. Advanced Chemical and Electrochemical Techniques for the Remediation of Petroleum Contaminatd Sites. Co-Supervised. Ph.D. Thesis, University Politehnica of Bucharest, Bucharest, Romania, 2010; University of Trento, Trento, Italy, 2009.

28. Guedes, P.; Mateus, E.P.; Couto, N.; Rodriguez, Y.; Ribeiro, A. Electrokinetic remediation of six emerging organic contaminants from soil. Chemosphere 2014, 117, 124-131. [CrossRef] [PubMed]

29. Sandu, C.; Popescu, M.; Rosales, E.; Bocos, E.; Pazos, M.; Lazar, G.; Sanroman, M.A. Electrokinetic-Fenton technology for the remediation of hydrocarbons historically polluted sites. Chemosphere 2016, 156, 347-356. [CrossRef] [PubMed]

30. Xu, S.; Guo, S.; Wu, B.; Li, F.; Li, T. An assessment of the effectiveness and impact of electrokinetic remediation for pyrene-contaminated soil. J. Environ. Sci. 2014, 26, 2290-2297. [CrossRef] [PubMed]

31. Camaselle, C.; Reddy, K.R. Development and enhacement of electro-osmotic flow for the removal of contaminants from soils. Electrochim. Acta 2012, 86, 10-22. [CrossRef] 
32. Decision No. 683/2015 Regarding the Approval of the National Strategy and the National Action Plan for the Management of Contaminated Sites in Romania. 2015. Available online: https:/ /lege5.ro/Gratuit/g42tonrxgm/hotararea-nr-683-2015-privind-aprobarea-strategiei-nationale-si-aplanului-national-pentru-gestionarea-siturilor-contaminate-din-romania (accessed on 25 November 2017).

33. Office of Environmental Health, Hazard Assessment (OEHHA). Air Toxics Hot Spots Program, Risk Assessment Guidelines, Guidance Manual for Preparation of Health Risk Assessments; Air Community and Environmental Research Branch, Office of Environmental Health Hazard Assessment, California Environmental Protection Agency: Sacramento, CA, USA, 2015; pp. 7-1-7-7.

34. United States Environmental Protection Agency (U.S. EPA). OSWER Directive 9200.1-120, Human Health Evaluation Manual, Supplemental Guidance: Update of Standard Default Exposure Factors; Office of Solid Waste and Emergency Response, United States Environmental Protection Agency: Washington, DC, USA, 2014.

35. Office of Environmental Health, Hazard Assessment (OEHHA). Air Toxics Hot Spots Program, Risk Assessment Guidelines, Guidance Manual for Preparation of Health Risk Assessments; Air Community and Environmental Research Branch, Office of Environmental Health Hazard Assessment, California Environmental Protection Agency: Sacramento, CA, USA, 2015; pp. 5-36-5-47.

36. Pawełczyk, A.; Božek, F. Health risk associated with airborne asbestos. Environ. Monit. Assess. 2015, $187,428$. [CrossRef] [PubMed]

37. Hunter, P.R.; Fewtrell, L. Acceptable Risk, Water Quality: Guidelines, Standards and Health; WHO: Geneva, Switzerland, 2001.

38. Bearden, D.M.; Ramseur, J.L. Oil and Chemical Spills: Federal Emergency Response Framework, Congressional Research Service; CRS Report; Library of Congress, Congressional Research Service: Washington, DC, USA, 2017.

39. Canadian Council of Ministers of the Environment (CCME). Canadian Soil Quality Guidelines. Carcinogenic and Other Polycyclic Aromatic Hydrocarbons (PAHS). Environmental and Human Health Effects. Scientific Supporting Document; Canadian Council of Ministers of the Environment (CCME): Gatineau, QC, Canada, 2008; pp. 1-210.

40. Connor, J.; Bowers, R.; McHugh, T.; Spexet, A. Software Guidance Manual RBCA Tool Kit for Chemical Releases; GSI Environmental Inc.: Houston, TX, USA, 2007; pp. 1-120.

41. Schoeny, R.; Poirier, K. Provisional Guidance for Quantitative Risk Assessment of Polycyclic Aromatic Hydrocarbons; EPA/600/R-93/089 (NTIS PB94116571); U.S. Environmental Protection Agency, Office of Research and Development, Office of Health and Environmental Assessment: Washington, DC, USA, 1993.

42. Lippman, S.M.; Hawk, E.T. Cancer prevention: From 1727 to milestones of the past 100 years. Cancer Res. 2009, 69, 5269-5284. [CrossRef] [PubMed]

(c) 2018 by the authors. Licensee MDPI, Basel, Switzerland. This article is an open access article distributed under the terms and conditions of the Creative Commons Attribution (CC BY) license (http://creativecommons.org/licenses/by/4.0/). 